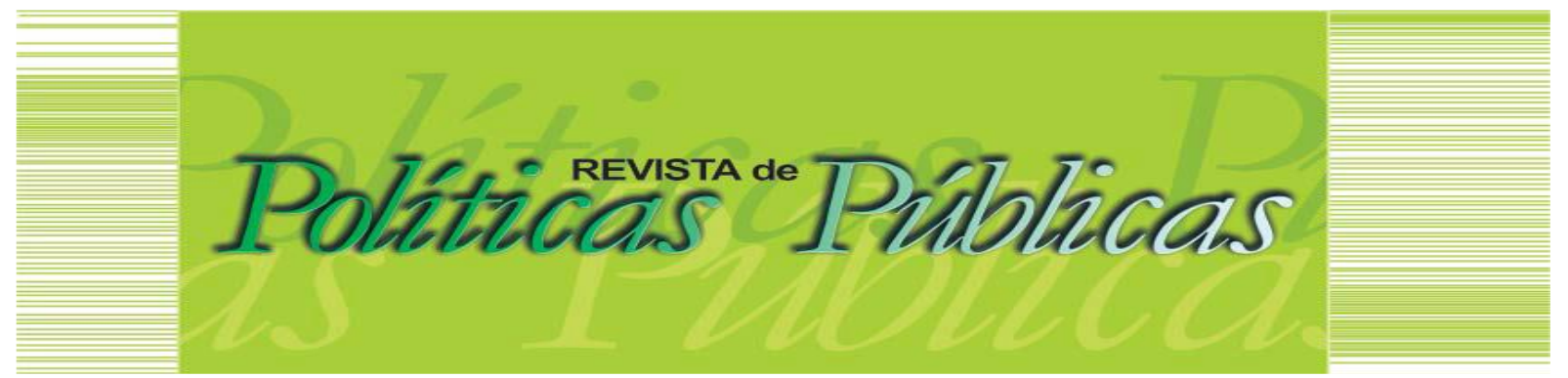

\title{
MOTORISTAS DE APLICATIVOS DE TRANSPORTE PRIVADO E A POSSIBILIDADE DE RECONHECIMENTO DO VÍNCULO EMPREGATÍCIO
}

\author{
Saulo Nunes de Carvalho Almeida 1 \\ Bianca Lima Barros ${ }^{2}$
}

\begin{abstract}
Resumo
O presente estudo se propôs a analisar a possibilidade de reconhecimento do vínculo de emprego de motoristas que utilizam aplicativo de transporte disponibilizado pela criadora e administradora deste. A justificativa para o objeto deste trabalho repousa na necessária investigação jurídica direcionada a enfrentar a ausência de legislação trabalhista específica para tratar a matéria. Como aspecto metodológico, adota o procedimento descritivo-analítico, pesquisa bibliográfica e jurisprudencial, de forma documental através de normas, livros e artigos científicos. Sendo capaz assim, de concluir que diante dos padrões e conceitos clássicos existentes, a relação apresentada e estudada não se enquadra como relação de emprego. Conclui, ainda, que se faz necessário rever conceitos e normas para adequá-las às novas relações de trabalho que surgem em detrimento da tecnologia.

Palavras-chave: Aplicativo Uber. Reconhecimento do Vínculo. Motoristas. Requisitos da Relação Empregatícia.
\end{abstract}

\section{DRIVERS OF PRIVATE TRANSPORTATION APPS AND THE POSSIBILITY OF RECOGNITION OF THE EMPLOYMENT LINK}

\begin{abstract}
The present study aimed to analyze the possibility of recognizing the employment link of drivers who use a transport application made available by the creator and administrator of this. The justification for the object of this work rests on the necessary legal investigation aimed at addressing the absence of specific labor legislation to deal with the matter. As a methodological aspect, we adopted the descriptive-analytical procedure, bibliographic and jurisprudential research, in a documental way through norms, books, scientific articles. Being able to conclude that in view of the existing classical patterns and concepts, the relation presented and studied does not fit as a employment relationship. However, it is also concluded that it is necessary to revise concepts and norms to adapt them to new work relations that arise at the expense of technology.
\end{abstract}

Keywords: Uber App. Recognition of the Bond. Drivers. Requirements of the employment relationship

Artigo recebido em: 12/07/2020 Aprovado em: 27/05/2021

DOI: http://dx.doi.org/10.18764/2178-2865.v25n1p354-369

\footnotetext{
1 Bacharel em Direito. Doutor em Direito Constitucional pela Universidade de Fortaleza - UNIFOR. Professor do Centro Universitário Católica de Quixadá e da UNIFANOR. E-mail: saulonunes@hotmail.com

2 Bacharel em Direito pelo Centro Universitário Católica de Quixadá. Membro do Grupo de Pesquisa Direito \& Desenvolvimento. E-mail: biancalimabarros@hotmail.com
} 


\section{INTRODUÇÃO}

Diante de uma perspectiva histórica é possivel constatar que o Direito do Trabalho tem sua gênese atrelada à industrialização. Foi o processo marcado pela difusão de novas máquinas que passou a ditar o ritmo de produção, tendo os trabalhadores que acompanhá-las, e laborarem para atingir a máxima produtividade (DELGADO, 2016). Assim, a regulamentação do trabalho adveio pela intervenção do Estado diante de reivindicações originadas por lutas sociais, ou seja, a origem de normas jurídicas que perfazem o direito do trabalho se evidenciaram, em face da imprescindibilidade do Estado de proteger a parte frágil dessa assimétrica relação, o trabalhador (POLI; HAZAN, 2013).

A contemporaneidade é marcada por um progresso científico singular na história da humanidade, desaguando em consideráveis mudanças na sociedade, principalmente no setor de tecnologia e comunicações, em razão da criação e difusão dos chamados aplicativos digitais. São sintomas daquilo que vem sendo reconhecido como uma nova revolução, a chamada Revolução Tecnológica.

Essa modernização permite surgir novos padrões de organização laboral, o que aparenta influenciar as clássicas relações de trabalho (MENDONÇA; ALMEIDA, 2014). No ápice desse cenário, é possível identificar os aplicativos direcionados à prestação de serviços eletrônicos, em que motoristas utilizam a plataforma, para exercer atividade que propicia aos usuários um transporte alternativo, caracterizado como transporte privado, sendo a referida plataforma administrada pela empresa que a criou.

Justifica a escolha do presente tema para esse ensaio jurídico o fato de que essas mudanças também afetam direta e indiretamente as relações de emprego, tanto pelo ponto de vista econômico, como social, e, especialmente, jurídico, resultando em demandas e discussões sobre sua configuração enquanto relação de trabalho autônomo ou de emprego subordinado.

A criação de dispositivos que intermediam e facilitam a prestação de serviços vem modificando a mobilidade urbana e resultando na geração de novas morfologias de trabalhos. Um contexto que trouxe grandes debates, em especial, por se tratar de um assunto novo, em que a legislação trabalhista falha em adequadamente regular essa espécie de relação específica; cabe aos juízes e Tribunais buscar (pela) a solução desses conflitos, caso a caso.

Como objetivo central, a presente pesquisa pretende analisar a natureza da atividade dos motoristas do Uber, explorando vertentes que entendem ou não o reconhecimento de uma relação empregatícia, partindo ainda da análise dos requisitos que devem se fazer presentes para caracterizar o 


\section{MOTORISTAS DE APLICATIVOS DE TRANSPORTE PRIVADO E A POSSIBILIDADE DE RECONHECIMENTO DO VÍNCULO}

EMPREGATÍCIO

vínculo. Mas também tem como finalidade realizar um estudo acerca do papel do direito do trabalho e sua função nuclear de adequadamente proteger o trabalhador.

Buscando enfrentar tais questionamentos, empregou-se o método descritivo-analítico, pois se buscou descrever e esclarecer o problema apresentado, demonstrando assim, também, o caráter exploratório. Para tanto, utilizou-se de pesquisa bibliográfica e jurisprudencial, de forma documental, por meio de leis, livros técnicos, artigos científicos, e demais ferramentas que abordem a temática.

\section{BREVES CONSIDERAÇÕES ACERCA DAS INFILTRAÇÕES TECNOLÓGICAS NAS RELAÇÕES DE TRABALHO}

Os avanços da tecnologia permitem uma multiplicidade de transformações nas formas de produção. Nesse contexto, novas morfologias de trabalho emergem e se difundem. Em consequência, a ideia clássica de subordinação jurídica começa a experimentar alterações, de modo que as tecnologias estão sendo cada vez mais utilizadas, e, por vezes, se tornando indispensáveis (CASSAR, 2017, p.12).

A modernização permite 0 nascimento de novos padrões de organização do trabalho, influenciando drasticamente as clássicas relações. Isso corresponde também aos aplicativos, programas que podem ser instalados em aparelhos móveis como celulares, tablets e smartphones, direcionados à prestação de serviços eletrônicos (BARBOSA, 2006) e a mobilidade urbana. Cada vez mais pessoas têm recorrido a esses com o objetivo de gerar renda extra, tendo em vista a ocorrência do alto índice de desemprego do país ${ }^{1}$, e ainda por supostamente oferecer mais flexibilidade, dentre outros aspectos que serão estudados no próximo capítulo (MENDONÇA; ALMEIDA, 2014).

É o caso do aplicativo ifood, que fornece serviço de delivery, ou seja, entrega de comida em domicílio. É uma plataforma virtual que reúne empresas que tem como objeto de venda a alimentação; nele são listados inúmeros restaurantes, pizzarias e lanchonetes reunidas em um só local, no qual o consumidor pode escolher, pedir e receber rapidamente em sua residência².

Outra plataforma que tem ganhado espaço chama-se Lavô; é um aplicativo de lavagem de carro, que oferece serviços de limpeza. A Lavô propõe parcerias e garante renda a quem quiser se juntar, pois disponibiliza cadastro para que pessoas interessadas em trabalhar lavando veículos, se registrem³

E como exemplo conclusivo, há os casos de motoristas que utilizam uma plataforma, para exercer atividade que propicia aos usuários o uso de um transporte alternativo, caracterizado como 
transporte individual privado, sendo a referida plataforma administrada pela empresa criadora. Inicialmente, a empresa Uber, hoje presente em mais de 600 (seiscentas cidades) pelo mundo4, foi vanguardista nesse serviço no mercado, dando margem a outras que foram surgindo (e continuam a surgir), como por exemplo, 99 (99Táxis), EasyTáxi e Cabify.

Diante da tecnologia se infiltrando nas relações de trabalho e emprego, alterando e criando novas modalidades (BARBOSA, 2006), a tendência moderna é que a intensidade desse processo continue a aumentar, o que possivelmente pode desaguar em uma espécie de crise dos requisitos jurídicos presentes nessas relações, já que as formas de trabalho e emprego estão se transformando (BRITO, 2007), ou até mesmo sendo "mascaradas", ao passo que empresas podem usar uma plataforma digital para estabelecer um contrato com um trabalhador, lucrar com o uso da força de trabalho do mesmo, mas, em virtude desse contrato ocorrer através de um aplicativo de intermediação, resultar na descaracterização da relação empregatícia. Desse modo, se torna necessário rever os conceitos e normas para adequar 0 que talvez possa se caracterizar como uma nova morfologia de relação de emprego.

\section{ASPECTOS INTRODUTÓRIOS ACERCA DO SURGIMENTO DO APLICATIVO UBER}

Como se sabe, o século XIX foi marcado pelo surgimento de formas de organização de trabalho como fordismo e toyotismo (DELGADO, 2016). Atualmente, um novo modelo de organização laboral tem emergido, ocupando espaço como fenômeno social e tecnológico. Através da evolução da internet e o surgimento de aplicativos, pessoas que possuem os mesmos interesses passaram a encontrar uma nova forma para se conectar, fazendo uma ligação entre demandas e ofertas de forma simples e rápida. Isso é o que se tornou conhecido como economia colaborativa, que tem transformado as relações de consumo e tem tornado possível a intermediação do trabalho de forma eletrônica (BARBOSA, 2006). Nesse contexto, surge o fenômeno da "uberização", que pode ser compreendido como um novo modelo de negócio, potencialmente capaz de se infiltrar em múltiplos setores do mercado e da economia (GONÇALVES, 2017).

Empresas que adotam a tecnologia têm transformado o mercado e atingido uma parcela da população que demanda produtos e serviços, e tem visto suas necessidades serem atingidas por um meio mais prático, rápido e eficaz (MENDONÇA; ALMEIDA, 2014). A empresa Uber se destaca como pioneira nesse meio, pois disponibilizou um serviço que se apresentou como engenhosa solução em meio a 


\section{MOTORISTAS DE APLICATIVOS DE TRANSPORTE PRIVADO E A POSSIBILIDADE DE RECONHECIMENTO DO VÍNCULO EMPREGATÍCIO}

problemas com transporte urbano e trânsitos desordenados, preenchendo, assim, uma necessidade social, já que não se encontravam serviços similares, com valores acessíveis e de fácil acesso.

Segundo informações do próprio site da Uber ${ }^{5}$ a empresa não está mudando apenas 0 transporte com a tecnologia criada por eles. A empresa se tornou uma das maiores do mundo, por contribuir na locomoção de pessoas e produtos, usando a tecnologia. A ideia inicial partiu de "um motorista particular para todos". Dita como simples, a ideia passou a ser algo tão abrangente, que, por conseqüência, transformou por completo o setor em que atua.

Em 2009 surgiu a UberCab, em São Francisco, nos Estados Unidos, a criação de um aplicativo para smartphones, ou seja, um programa instalado em aparelho móvel como o celular, o qual possibilitaria a solicitação de viagens "ao simples toque de um botão". Mas somente no ano de 2010, o aplicativo iniciou suas atividades, ao conectar um usuário a um carro da cor preta. E em seguida, a empresa adota a palavra Uber, retirando assim, "cab" (que significa táxi), delimitando, desta forma, o marco de separação com o setor ${ }^{6}$.

A partir de então, a empresa consolidou a marca Uber. Após três anos da concepção da ideia, a empresa lança a Uber, em Paris, dando início ao seu processo de internacionalização. Em 2012, nos Estados Unidos, usuários passam a pedir sorvetes através do aplicativo, demonstrando que a tecnologia por meio da Uber não se mostrava apenas como transporte de passageiros, mas também de produtos. $\mathrm{A}$ seguir, a empresa foi se estendendo às demais cidades e países, como Austrália, México, chegando assim à América Latina em 20137.

Ao final do ano de 2015, 1 bilhão de viagens foram registradas desde o lançamento, e em menos de seis meses já se chegavam a 2 bilhões de viagens. Encerrando o ano de 2016, com a uber presente em 500 cidades. Em maio de 2017, ou seja, em menos de um ano, se atingiam 5 bilhões de viagens. Atualmente, segundo as pesquisas divulgadas pela própria empresa, a Uber está presente em mais de 600 cidades em 65 países, possuindo no mundo mais de 3 milhões de motoristas parceiros. Sendo registradas, em média, 15 milhões de viagens por dia no mundo, e mais de 75 milhões de usuários.

No Brasil, os serviços prestados pela empresa chegaram em 2014, inicialmente no Rio de Janeiro, posteriormente em São Paulo, Belo Horizonte e Brasília. A Uber está em mais de 100 cidades brasileiras, e com mais de 500 mil motoristas parceiros até outubro de 2017. No país, são oferecidas cinco modalidades de serviços; uberX, oferece carros com quatro portas e ar condicionado, UberSELECT, são carros mais confortáveis e espaçosos, porém oferece um preço mais alto que o UberX, em média, 20\% 
maior. O UberBLACK, nesse caso, o serviço se restringe a carros pretos e de luxo, de modelo tipo sedan, que possuem banco de couro e ar condicionado sempre ligado. Por fim, oferece também, o UberPOOL.

\subsection{Funcionalidade e uso do aplicativo uber pelos motoristas e usuários}

Conforme explicitado, a empresa Uber desenvolveu o aplicativo direcionado à prestação de serviços eletrônicos de transporte, em que motoristas utilizam a plataforma virtual, para exercer atividade que propicia aos usuários um transporte alternativo, caracterizado como transporte público privado, como será visto mais adiante. A citada plataforma opera através de um aplicativo E-hailing, ou seja, é possível requisitar um transporte individual por meio de um dispositivo, baseado em tecnologia disruptiva em rede, que corresponde a uma inovação tecnológica, diferenciada de modelos já existentes.

Esse dispositivo faz a ponte entre passageiros e motoristas e foi projetado com o objetivo de ajudar as pessoas a chegarem a seus destinos, possuindo desde opções simples de navegação, como pagamento eletrônico.

Para isso, o motorista, tido como parceiro da Uber, deverá ser "profissional". A empresa exige que esse possua a autorização necessária para tanto, devendo ter em sua carteira nacional de habilitação a informação EAR (exerce atividade remunerada). Dessa forma, o pretenso motorista faz um cadastro no site da Uber, e passa por uma checagem de informações e de segurança, inclusive disponibilizando todos os dados do carro em que utilizará nas viagens ${ }^{8}$.

Após o referido cadastro, o motorista poderá iniciar suas atividades utilizando o aplicativo no qual tem acesso com senha pessoal e intransferível, selecionando o carro cadastrado. Após 0 procedimento, a qualquer momento será possível receber uma chamada de um usuário que está solicitando uma viagem. Ao aceitar, o aplicativo apontará a localização e alguns dados do passageiro.

Quando o passageiro adentra o veículo, considera-se a viagem iniciada. 0 aplicativo mostra a rota em tempo real até o fim da corrida, bem como indica o valor da mesma. Os motoristas possuem a obrigação de repassar para a Uber $20 \%$ do valor que recebem em cada viagem.

Diante do exposto, ficou demonstrado que a empresa surgiu com uma proposta inovadora no mercado e seus serviços trouxeram aos consumidores mais mobilidade, simplicidade, comodidade e segurança. Há disponibilidade de carros de luxo, com água, doces, revistas e preços mais acessíveis, tendo por base os serviços semelhantes existentes até então. De outra forma a empresa também surgiu como uma oportunidade no mercado de trabalho, possibilitando que milhares de pessoas tenham a chance de adquirir renda, conectando-os com outras pessoas que desejam se deslocar. 


\subsection{Descrição jurídica do contrato entre motoristas e a empresa Uber}

Para que os motoristas se cadastrem na empresa e passem a prestar serviços, é necessário que concordem com um amplo conjunto de termos e condições gerais, englobando a Política de Privacidade e o Código de Conduta da Comunidade Uber.

Todo o processo é digital. São requisitados telefone e email, e caso o motorista tenha recebido indicação de um outro motorista já parceiro, este pode repassar um código promocional, que poderá ser usado no cadastro. Com isso, algumas documentações pessoais são enviadas através do próprio aplicativo, e a empresa realiza uma verificação de segurança, em que o cadastro será analisado.

Com o Registro e Licenciamento de Veículo o motorista pode começar a dirigir utilizando 0 sistema da Uber. O contrato estabelece que, esporadicamente, a verificação deve ser refeita, ou seja, a qualquer momento a empresa poderá rever as documentações necessárias e requeridas.

O relacionamento contratual entre motorista e empresa, como dito anteriormente, é estabelecido por meio dos termos e condições impostos pela própria empresa que poderá, inclusive, incluir termos adicionais, alterar ou encerrar o contrato, a qualquer momento e por qualquer motivo, deixando de oferecer ou negar o acesso a sua plataforma.

A partir daí o motorista poderá receber solicitações demandadas por usuários devidamente cadastrados no aplicativo. O contrato estabelece como ocorrerá o processo de viagens, ressaltando que 0 motorista, como um trabalhador autônomo, é responsável pelas ferramentas ou materiais que se fizerem necessários para a efetivação do serviço. Ao aceitar uma solicitação de viagem feita por um usuário, 0 motorista, automaticamente, cria uma relação contratual direta com o passageiro. E, é responsável pelo transporte deste, até o seu destino, e ainda, por qualquer obrigação que surgir decorrente da viagem.

Um outro termo do contrato especifica que a empresa não controla ou administra o motorista, e que o motorista é quem decide quando, onde e por quanto tempo irá utilizar o aplicativo, porém, haverá limites ao tempo em que o motorista dirigirá de forma contínua, por motivos de segurança pública. Além do que, ainda decide quando aceitar, rejeitar ou ignorar uma solicitação de viagem. A empresa esclarece ainda, que é de total escolha do motorista exercer outra atividade remuneratória, inclusive utilizar outros aplicativos semelhantes. 
A cláusula contratual que diz respeito ao pagamento aduz que o motorista tem o direito de cobrar um preço por cada viagem, sendo este calculado com base na soma de um preço variável dos Serviços de Transporte e uma parcela fixa dos serviços. Envolve distância e/ou quantidade de tempo, podendo variar conforme a região, a oferta e a demanda local. Ao aceitar a viagem, o motorista concorda com 0 valor recomendado pela Uber. Nesse caso, a Uber é o agente de cobrança de pagamento, recebendo do usuário através do processamento de pagamentos no aplicativo (cartão de crédito/débito). 0 preço é repassado, no mínimo, semanalmente ao motorista.

Em relação aos impostos, o motorista é totalmente responsável por qualquer obrigação tributária e tributos sobre seus próprios rendimentos. Além do que é responsável pelos custos e manutenções do aparelho móvel que utilizar para acessar o aplicativo, bem como plano de dados e qualquer ferramenta utilizada pelo motorista para prestar o serviço.

A rescisão contratual pode ser realizada tanto pelo motorista como pela empresa por qualquer motivo e tempo, sem qualquer ônus ou indenizações, porém, deve haver uma notificação à outra parte com antecedência de sete dias, ou imediatamente, sem aviso prévio, no caso de não cumprimento das exigências das cláusulas contratuais, configurando violação.

No código de conduta está previsto que o motorista parceiro pode perder o direito de acesso a Uber em algumas circunstâncias, dentre elas: avaliação por estrelas. Para isso, a Uber considera as últimas 500 (quinhentos) viagens do motorista, a taxa de cancelamento do parceiro, a avaliação por estrelas e os comentários sobre a viagem.

O fato de recusar viagens repetidas vezes poderá fazer com que o motorista seja desconectado, em virtude da possibilidade que se este estiver impossibilitado de aceitar viagens, poderia apenas se desconectar do sistema, reativando quando necessário.

Por fim, a relação estabelecida contratualmente é exclusivamente de partes contratantes. A Uber elenca em seu contrato que o mesmo não constitui um contrato de trabalho, nem relação de agenciamento e não dá autorização para que o motorista se apresente como tal.

\section{A RELAÇÃO JURÍDICA ENTRE MOTORISTA E EMPRESA DO APLICATIVO DE TRANSPORTE À LUZ DOS TRIBUNAIS}

O uso do aplicativo de transporte privado Uber, dotado de pioneirismo e crescimento acelerado, tanto de usuários quanto de motoristas, tem significado, também, diversas ações trabalhistas 


\section{MOTORISTAS DE APLICATIVOS DE TRANSPORTE PRIVADO E A POSSIBILIDADE DE RECONHECIMENTO DO VÍNCULO EMPREGATÍCIO}

impetradas por motoristas nos Estados Unidos e em vários países em que o serviço está disponível ${ }^{9}$, inclusive perante a justiça brasileira, requerendo reconhecimento de vínculo de emprego com a referida empresa.

Apesar de ser considerada recente, a discussão acerca do reconhecimento da relação de emprego entre motoristas e a empresa Uber já foi objeto de discussão em diversos juízos e Tribunais do Trabalho no país, tendo sido emitido decisões de naturezas opostas, conforme será apresentado a seguir.

\subsection{Análise crítica de decisão favorável ao reconhecimento do vínculo empregatício}

A primeira decisão no Brasil em que foi reconhecido o vínculo de emprego entre o motorista e a empresa administradora do aplicativo Uber, surge em fevereiro de 2017. A referida decisão ocorreu na $33^{a}$ Vara do Trabalho de Belo Horizonte, oportunidade em que o magistrado descreveu o serviço como um fenômeno que denota um novo modelo de organização do trabalho, e constatou a presença dos elementos essenciais para caracterização do vínculo empregatício, condenando a empresa ao pagamento das verbas de caráter trabalhista.

Na demanda do motorista contra a Uber, o mesmo afirmou ter trabalhado de fevereiro a dezembro de 2015, com o transporte de passageiros na cidade de Belo Horizonte, e que foi imotivadamente dispensado, requerendo a declaração do vínculo e todas as verbas rescisórias correspondentes, inclusive, horas extras; adicional noturno e ainda, receber valores gastos com combustível, água e balas que eram oferecidas aos passageiros.

O magistrado, em sua decisão, entendeu que naquela relação estavam presentes todos os elementos legais necessários para a existência do vínculo. Trouxe, inclusive, conceitos históricos e sociais para decidir. Dando o nome "uberização" às relações laborais, que significaria um novo padrão de organização do trabalho.

Partindo para a análise dos elementos essenciais da relação de trabalho no caso em discussão, o magistrado constatou que os elementos pessoa física e pessoalidade ficaram evidenciados quando a empresa exigiu um cadastro pessoal prévio do motorista, bem como, requisitou deste o envio de distintos documentos pessoais e certidões de bons antecedentes para que seu cadastro fosse aprovado. Ainda mais, quando se constata o fato de que não pode o motorista ceder sua conta para que outra pessoa a utilize, denotaria o caráter personalíssimo do contrato. 
Quanto à onerosidade, que representa o pagamento pela prestação do serviço, foi identificada através da forma como a empresa conduzia a política de pagamento, ao passo que delimitava os preços das viagens, as formas de pagamento e possíveis descontos, definia que o motorista receberia o valor real correspondente ao trabalho executado.

$O$ fato de o cadastro se tornar inativo depois de determinado tempo sem ser utilizado pelo motorista, demonstrava que o mesmo atendia as demandas pelos serviços de transporte de forma intermitente, e que a empresa recebia o percentual de 20 a $25 \%$ do preço cobrado por viagem, não ficando a cargo do motorista o ônus/bônus da captação de clientes. E, ainda, premiava os motoristas quando estes alcançavam condições estipuladas pela empresa, demonstrando, assim, a existência de relação onerosa.

0 magistrado denotou a existência do elemento da não eventualidade, pois no caso em comento, percebeu-se que durante o período trabalhado, o autor da ação laborou de forma habitual. Ainda enfatizou que a empresa emitia alertas aos motoristas, informando que a falta de ativação/ocorrências de viagens por um mês, ou até por uma semana, poderia gerar a exclusão da conta destes. Concluiu que a empresa atuava, na realidade, como fornecedora de serviço de transporte.

Por fim, o juiz do trabalho destacou a subordinação, alegando que o motorista estava a todo 0 momento submisso às ordens quanto à forma de desenvolver o serviço, sujeito a controle e sanções, já que a ele era imputada uma vasta gama de regras e padrões de atendimento, podendo ocasionar a perda do acesso ao aplicativo. Nesse contexto, o magistrado elencou que o controle exercido pelo empregador adquiria uma nova roupagem de gestão e fiscalização, através de sistemas e redes.

Com base na presença dos elementos caracterizadores da relação de emprego foi julgado 0 processo, condenando a empresa Uber em virtude do reconhecimento do vínculo de emprego entre as partes (aplicação do princípio da primazia da realidade).

Oportuno destacar que em março de 2017, a decisão referente ao processo supracitado seria revertida pelo TRT da $3^{\mathrm{a}}$ região de forma unânime em que, em síntese, restou entendido não se tratar de uma relação empregatícia por não identificar os elementos da pessoalidade e nem da subordinação na relação. Seguindo essa mesma inteligência, outras decisões já confirmaram que não há existência de vínculo de emprego, como dito. A seguir estudar-se-á uma decisão nesses termos.

\subsection{Análise crítica de decisão desfavorável ao reconhecimento do vínculo}




\section{MOTORISTAS DE APLICATIVOS DE TRANSPORTE PRIVADO E A POSSIBILIDADE DE RECONHECIMENTO DO VÍNCULO EMPREGATÍCIO}

A decisão selecionada é da $37^{a}$ Vara do Trabalho, também de Belo Horizonte, em janeiro de 2017. Nesse caso, em síntese, o motorista também alegou ter sido imotivadamente dispensado sem receber qualquer verba trabalhista, requerendo o reconhecimento do vínculo de emprego, e consequentemente, o recebimento de múltiplas verbas rescisórias, como horas extras, adicional noturno e ainda, danos morais.

Uma análise da decisão inicia com o destaque de que estaríamos diante de um cenário de ausência de subordinação do motorista para com a empresa, o que já prejudicaria o reconhecimento do vínculo em questão. Baseando-se nas provas apresentadas, o magistrado concluiu que as reclamadas não emitiam ordens e nem determinações ao motorista, e sim, recomendações com os modos de comportamento deste para com os clientes.

Não havia regras quanto aos horários para utilizar o aplicativo, podendo o motorista deliberar sobre seus horários, usando o aplicativo a qualquer tempo e sem avisos quanto ao momento em que utilizaria ou deixaria de usar. Detectou-se a ausência de exclusividade e total ausência de controle da jornada de trabalho. E que demais determinações correspondem às obrigações que são comumente estabelecidas em relações contratuais de emprego. Caracterizando, assim, a eventualidade do trabalho prestado.

Em relação aos preços estipulados pelo aplicativo, não se caracterizaria o vínculo, posto que, seria apenas, uma obrigatoriedade de escolha do motorista, caso este pretendesse utilizar 0 aplicativo, fazendo assim, uma comparação aos contratos de representação comercial. Além disso, a remuneração não aparentava se enquadrar no conceito de salário, considerando que o motorista possui ampla liberdade em sua atividade, montando seus próprios horários, sem nem ao menos necessitar de autorização para desligar 0 aplicativo.

Com base na subordinação estrutural, o magistrado em questão afirma que esta se caracteriza pela inserção do trabalhador na sistemática de funcionamento proposta, conformando-se a essa estrutura, mesmo que não receba ordens diretas. Restando, portanto, que a Uber fornece apenas serviços de tecnologia, e sendo assim não cabe inserir o motorista como empregado. Julgando o processo, portanto, improcedente.

\subsection{Análise crítica do reconhecimento ou não da relação empregatícia com base nas decisões jurisprudenciais e suas perspectivas}


Alcançando a conclusão desse tópico, partimos, agora, para uma leitura crítica das decisões acima estudadas acerca da questão do reconhecimento do vínculo empregatício na relação jurídica existente entre motorista e empresa do aplicativo de transporte. Inicialmente, adequado compreender que, até o presente momento, não existe regulamentação trabalhista acerca da relação contratual existente entre motoristas e as empresas de aplicativos de transporte (ou aplicativos similares utilizados em outros setores). Nesse contexto, o trabalho vem sendo prestado de forma autônoma e sem vínculo empregatício.

Observou-se que a relação estabelecida contratualmente é de partes contratantes independentes. A empresa Uber elenca em seu contrato que não constitui um contrato de trabalho, não cria uma relação de emprego, nem relação de agenciamento e não dá autorização para que o motorista se apresente como empregado, agente ou representante da empresa. E, ainda, que essa é uma empresa de tecnologia que desenvolveu um aplicativo que conecta provedores e usuários de serviço de transporte privado, sendo, portanto, "a Uber que presta um serviço ao motorista - e não o inverso".

Como geralmente ocorre na seara trabalhista, a análise pela existência ou não de uma relação de emprego deverá sempre orbitar ao redor da efetivação do princípio da primazia da realidade. Diante do conteúdo jurídico desse princípio, aspectos formais e/ou contratuais são postos em segundo plano, devendo-se buscar assegurar os aspectos reais. Portanto, por mais que se pactue um contrato expressamente estabelecendo que a relação jurídica não corresponda a uma relação de emprego, se os requisitos do mesmo se fizerem presentes, ele deverá sim ser reconhecido um contrato empregatício.

Partindo dos pressupostos caracterizadores da relação de emprego, uma análise das decisões opostas e descritas neste trabalho, pode-se identificar a presença aparente de alguns elementos. Incialmente aparenta ser inquestionável que existe um liame de caráter oneroso presente na relação contratual. Porém, a onerosidade da relação de emprego se refere não a uma espécie de "salário", e sim uma contraprestação por um serviço não dotado de habitualidade (DELGADO, 2016), em que os motoristas recebem apenas pelas viagens que escolherem realizar.

Embora o serviço tenha que ser realizado por pessoa física, e não possa o motorista ceder sua conta a outro, no momento em que se solicita uma viagem, este pode ser substituído por qualquer outro motorista que se encontre próximo ao local de onde um usuário está requerendo a corrida, levando a reflexão sobre a existência ou não da pessoalidade (BARBOSA, 2006).

Ademais, a empresa Uber não impede que o motorista preste serviço para outras empresas semelhantes, ou seja, outros aplicativos concorrentes, ou qualquer outro serviço. Afinal, o motorista pode ficar inativo de sua conta a qualquer momento e horário, podendo retornar às atividades também quando 


\section{MOTORISTAS DE APLICATIVOS DE TRANSPORTE PRIVADO E A POSSIBILIDADE DE RECONHECIMENTO DO VÍNCULO EMPREGATÍCIO}

assim entender, ou seja, possui total e completa liberdade com relação a horários. Esse nem mesmo necessita informar sua "escala" ao aplicativo, podendo prestar serviços de forma eventual. Esse cenário descaracteriza o elemento da habitualidade.

Quanto à subordinação jurídica, refletida como o poder de direção empresarial, em uma relação empregatícia se denota o fato de o empregado ter que acatar as ordens e os comandos emitidos pelo empregador. De acordo com Gabriela Neves Delgado (2006, p.191), a subordinação opera hoje por outras vias que não só a direta e incisiva. "Embora mais viva do que nunca, torna-se possível sem a necessidade de um ambiente empresarial ou de um espaço fixo predeterminado para legitimar-se."

Todavia, para se caracterizar a subordinação no contrato de trabalho é necessário que 0 modo da prestação seja dirigido pelo empregador. Mas como já salientado, não existem regras quanto a horários de utilização do aplicativo, nem mesmo se fazendo necessário ao motorista informar qualquer inativação definitiva ou temporária, ou seja, não há tentativa de controle da jornada laboral. Na verdade, a relação retratada viabiliza maior flexibilidade e autonomia ao trabalhador, pois este passa a ter controle sobre sua atividade.

À guisa de conclusão, é patente que a difusão das novas tecnologias viabilizam uma maior flexibilidade e autonomia ao trabalhador. Porém, percebe-se também que os requisitos tradicionais necessários para caracterizar uma relação empregatícia, conforme o ordenamento jurídico vigente, não está "preparado" para abarcar as inovações da organização do trabalho e as formas de prestação de serviço em meio ao intenso processo de infiltração da tecnologia nos distintos campos da vida. A relação de trabalho atual entre motorista e uber não experimenta a tutela protetiva dos direitos sociais trabalhistas por não se enquadrar nos parâmetros existentes na norma celetista, distanciando-se das formas tradicionais de trabalho. Todavia, o questionamento mais complexo que devemos enfrentar é: "mas será que deveriam se enquadrar"?

Diante do exposto, resta evidenciado que não estamos diante de uma relação jurídica de emprego. Contudo, pode ser problemático que assim continue a ser para fins futuros. Torna-se necessário repensarmos que relações análogas como a existente entre motorista e uber irão difundir-se em múltiplos campos da sociedade ("uberização") e essas necessitarão experimentar uma adequada tutela por parte dos direitos sociais trabalhistas. Para isso, devemos revisitar conceitos juslaboralistas, ponderar sobre os elementos tradicionais caracterizadores da relação de trabalho e quão adequados os mesmos continuarão 
a ser no futuro, em virtude da difusão de novas tecnologias e a forma como essas tendem a moldar a organização de trabalho moderna.

\section{CONSIDERAÇÕES FINAIS}

É axiomático que as relações de trabalho na contemporaneidade sofrem grande influência dos avanços da tecnologia da informação. Tecnologias de fronteiras têm se infiltrado e, por vezes, de forma determinante, alterado a própria sistemática de organizações laborais e de emprego. Por serem tão eficientes, as tecnologias que envolvem mobilidade tornaram possíveis as prestações de serviços de forma prática, rápida e acessível; têm ganhado força e sido utilizadas por uma quantidade tão vasta de pessoas.

Porém, essas circunstâncias têm implicado em uma multiplicidade de dificuldades e discussões que necessitam a análise, tentativa de solução e consequente intervenção do Poder Judiciário, como é o caso emblemático da empresa Uber e os motoristas que prestam serviços mediante o uso de seu aplicativo.

Considerando o conceito atual de subordinação jurídica e os demais elementos que devem se fazer presentes nas relações empregatícias, bem como, os demais estudos e entendimentos que este trabalho englobou, é possível concluir que o serviço prestado por motoristas que se utilizam de aplicativos para exercer suas profissões não possuem os requisitos normativos que o direito brasileiro atrela a um vínculo empregatício.

Há que se ressaltar que grande parte das empresas se utilizam de formas emergentes de tecnologias, sejam para disponibilizar ferramentas e mecanismos informatizados, seja para otimizar as atividades e produção. Entretanto, até que ponto esse novo modelo de organização pode estar desaguando em um contexto em que empresas angariam trabalhadores, mediante 0 uso de tais ferramentas, mas os mesmos são deslocados para fora do espectro dos direitos trabalhistas básicos?

Estamos diante de um novo modelo de organização econômica, em que a utilização de tecnologias se estende, gerando modificações de grande proporção na forma como prestamos serviços. Todavia, o ramo da ciência jurídica conhecida como direito do trabalho não se mostra preparada para enfrentar esse contexto. Por esse motivo se faz imperativo ponderar sobre como conceitos tradicionais (como os requisitos legais de uma relação de emprego) deverão se ajustar às novas relações de trabalho. 


\section{REFERÊNCIAS}

BARBOSA, Robson Duarte. O teletrabalho dentro de uma visão mais ampla da subordinação jurídica. Revista Direito e Liberdade, v. 3. n.2. set., 2006.

BRITO, Lydia Maria Pinto. BARROS, Sônia Maria Pinheiro. Pressão, sobrecarga de trabalho e realização de tarefas fora da jornada de trabalho - a face mais objetiva do assédio moral. Revista Direito e Liberdade, v.6, n.2, jan/jun, 2007.

CASSAR, Vólia Bomfim. Direito do Trabalho. 14 ed. rev. e atual. E ampl. Rio de Janeiro: Forense; São Paulo: Método, 2017.

DELGADO, Mauricio Godinho. Curso de Direito do Trabalho. 15. ed. São Paulo: Ltr, 2016.

DELGADO, Gabriela Neves. Direito Fundamental ao Trabalho Digno. São Paulo: LTr, 2006.

DELGADO, Maurício Godinho. Curso de Direito do Trabalho. 15. ed. São Paulo: LTr, 2016.

GONÇALVES, Márcio Toledo. Sentença no processo n 0011359-34-2016.5.03.0112. Disponível em: http://www.migalhas.com.br/arquivos/2017/2/art20170214-02.pdf. Acesso em: 23 mar. 2018.

LEITE, Carlos Henrique Bezerra. Curso de direito do trabalho. 9 ed. São Paulo: Saraiva, 2018.

MENDONÇA, Maria Lírida Calou de Araújo. ALMEIDA, Saulo Nunes de Carvalho. Crise do capitalismo e a necessária mutação de paradigmas nas relações justrabalhistas. Revista Pensar. v. 19, n.1, Fortaleza, 2014.

POLI, Luciana Costa. HAZAN, Bruno Ferraz. A função social dos contratos como instrumento para a sustentabilidade. Revista Direito e Liberdade, v.15, n.1, jan/abr, 2013.

TST. AGRAVO DE INSTRUMENTO EM RR: processo n 2058-43.2012.5.02.0464. Relator: Ministro Cláudio Brandão. Disponível em:https://www.jota.info/wpcontent/uploads/2017/11/268717_2014_1509094800000-1.pdf?x48657. Acesso em: 15 nov. 2018.

TRT-3. RECURSO ORDINÁRIO: processo no 0011359-34.2016.5.03.0112. Relatora: Desembargadora Maria Stela Álvares da Silva Campos. Disponível em: https://www.conjur.com.br/dl/trt-reforma-decisaouberizacao.pdf. Acesso em: 11 nov. 2018.

\section{Notas}

${ }^{1}$ No último trimestre de 2017, a taxa de desemprego atingiu $11,8 \%$ e subiu para $13,7 \%$ no primeiro trimestre do ano de 2018 , segundo o IBGE - Instituto Brasileiro de Geografia e Estatística.

2 Disponível em www.ifood.com.br. Acesso em 10/01/2019.

3 Disponível em www.lavo.online/. Acesso em 10/01/2019. 
${ }_{4}^{4}$ Disponivel em www.uber.com. Acesso em 15/01/2019.

${ }^{5}$ Disponível em www.uber.com. Acesso em 10/01/2019.

${ }^{6}$ Disponível em www.uber.com. Acesso em 10/01/2019.

7 Demonstrando a diversidade da Uber, e do serviço proporcionado por esta, a empresa lança uma parceria com abrigos de animais dos Estados Unidos, onde permitia que os usuários solicitassem gatinhos por alguns minutos, sendo o lucro revestido para os abrigos, esse foi o chamado Uber GATINHOS.

8 Disponível em www.uber.com. Acesso em 10/01/2019.

${ }^{9}$ No ano de 2017 em decisão proferida pelo Tribunal Trabalhista de Londres, foi compreendido que os motoristas cadastrados no aplicativo Uber devem ser considerados empregados da empresa, sendo assegurada sua integralidade de direitos. 